\title{
Biocompatibility and Bioactivity of Four Different Root Canal Sealers in Osteoblastic Cell Line MC3T3-El
}

\author{
Nu-Ri Jun', Sun-Kyung Lee ${ }^{2}$, and Sang-Im Lee Le, $^{1, \dagger}$ \\ 'Department of Public Health, General Graduate School, Dankook University, Cheonan 31116, ${ }^{2}$ Department of \\ Biomedical Laboratory Science, Donggang University, Gwangju 61200, ${ }^{3}$ Department of Dental Hygiene, College \\ of Health Science, Dankook University, Cheonan 31116, Korea
}

\begin{abstract}
Background: Endodontic sealers or their toxic components may become inflamed and lead to delayed wound healing when in direct contact with periapical tissues over an extended period. Moreover, an overfilled sealer can directly interact with adjacent tissues and may cause immediate necrosis or further resorption. Therefore, the treatment outcome conceivably depends on the endodontic sealer's biocompatibility and osteogenic potential. This study aimed to evaluate the cell viability and osteogenic effects of four different sealers in osteoblastic cells.

Methods: AH Plus (resin-based sealer), Pulp Canal Sealer EWT (zinc oxide-eugenol sealer), BioRoot RCS (calcium silicate-based sealer), and Well-Root ST (MTA-based calcium silicate sealer) were mixed strictly according to the manufacturer's instructions, and dilutions of sealer extracts $(1 / 2,1 / 5$ and 1/10) were determined. Cell viability was measured using the water-soluble tetrazolium-8 (WST-8) assay. Differentiation was assessed by alkaline phosphatase (ALP) activity and mineralized nodule formation by Alizarin Red S staining.

Results: The cell viability of the extracts derived from the sealers excluding Well-Root ST was concentration dependent, with sealer extracts having the least viability at a $1 / 2$ dilution. At sealer extract dilution of $1 / 10$, the test groups showed the same survival rate as that control group, with the exception of BioRoot RCS. Among all experimental groups, BioRoot RCS showed the highest cell viability after 48 hours. The ALP activity was significantly higher in a concentration-dependent manner. Furthemore, all four materials promoted ALP activity and mineralized nodule formation compared to the control at 1/10 dilutions.

Conclusion: This is the first study to highlight the differences in biological activity of these four materials. These results suggest that the composition of root canal sealers appears to alter the form of biocompatibility and osteoblastic differentiation.
\end{abstract}

Key Words: Biocompatibility, Cell differentiation, Osteoblasts, Root canal filling materials

\section{Introduction}

Endodontic sealers conventionally used to fill root canals affect the prognosis of endodontic treatment ${ }^{1)}$. Although endodontic sealants are designed to remain within root canals during endodontic treatment, they sometimes extrude through apical narrowing ${ }^{2,3)}$. The anatomical structure of the apical foramen, lateral canals, and dentinal tubules may allow tissue fluids to easily penetrate the root canal system, leading to degradation of the sealing material and subsequent leaching of various components ${ }^{4)}$. When it is in direct contact with the periapical tissue for a long time, endodontic sealers or their toxic components may become inflamed and delay wound healing ${ }^{5)}$. Moreover, the overfilled sealer may interact with adjacent tissues, resulting in immediate necrosis or further resorption ${ }^{6}$. Even in the absence of extrusion, root canal sealer may release soluble toxic substances into the periapical tissues, affecting local bone metabolism ${ }^{7}$. Therefore, treatment outcomes conceivably depend on the endodontic sealer's biocompatibility and 
osteogenic potential.

Numerous types of root canal sealers are used in clinical settings, such as; AH Plus (resin-based sealer; Dentsply/ De Trey, Konstanz, Germany), Pulp Canal Sealer EWT (zinc oxide-eugenol sealer; SybronEndo, Glendora, CA, USA), BioRoot RCS (calcium silicate-based sealer; Septodont, St. Maur-des-Fosses, France), and Well-Root ST (MTA-based calcium silicate sealer; Vericom, Chuncheon, Korea). AH Plus is a paste-to-paste material that exhibit an amine polymerization reaction contained in epoxy resin. It is a thermoplastic epoxy resin-based sealer with excellent physicochemical properties, despite a lack of bioactive potential ${ }^{8)}$. Pulp Canal Sealer EWT is a zinc oxide eugenol sealer consisting of a powder base and liquid catalyst. Several studies have demonstrated, its toxic potential due to isolated eugenol released in mixing zinc oxide and eugenol ${ }^{9,10)}$. However, studies show that Pulp Canal Sealer EWT produces better tissue organization than epoxy resin-based sealer after subcutaneous implantation in rat connective tissues ${ }^{11)}$. BioRoot RCS is a bioactive mineral root canal sealant based on "active biosilicate technology," an innovative mineral microagglomerating chemical ${ }^{12)}$. BioRoot RCS mainly consists of tricalcium silicate and zirconium oxide powder mixed with a liquid containing calcium chloride. This sealer is biocompatible and has a positive effect on biological activity and cell metabolism ${ }^{13)}$. Well-Root ST, a white MTA calcium silicate sealer, incorporates bioactive glass. A previous study showed that, sealers containing MTA are highly biocompatible and stimulate mineralization ${ }^{14)}$. They exhibit bioactivity by encouraging differentiation and migration of cells that produce hard tissue ${ }^{15)}$.
The biocompatibility and bioactivity of two newly developed calcium silicate-based sealers have not been fully elucidated. Therefore, this study aimed to evaluate the cell viability and osteogenic effects of four sealers on MC3T3-E1 cells which are osteoblastic cell lines, at different dilutions.

\section{Materials and Methods}

\section{Sealer extract preparation}

Four root canal sealers were evaluated (Table 1): AH Plus (resin-based sealer), Pulp Canal Sealer EWT (zinc oxide-eugenol sealer), BioRoot RCS (calcium silicatebased sealer), and Well-Root ST (MTA-based calcium silicate sealer). One spoon of BioRoot RCS powder was mixed with five drops of liquid, and the other sealers $(\mathrm{AH}$ Plus, EWT, Well-root ST) were mixed in a 1:1 ratio, according to the manufacturer's instructions. Disks of all root canal sealers were packed into Teflon molds (total sample weight: $2 \mathrm{~g}$; size $=6-\mathrm{mm}$ diameter and $2-\mathrm{mm}$ height) and stored at $37^{\circ} \mathrm{C}$ and $100 \%$ humidity for 24 hours to achieve complete setting. After setting, the eluates of the different materials were extracted under sterile conditions using $\alpha$-minimal essential medium ( $\alpha$-MEM; Welgene, Gyeongsan, Korea). The ratio between the weight of the sample and volume of the culture medium was $0.05 \mathrm{~g} / \mathrm{mL}$ for 72 hours at $37^{\circ} \mathrm{C}$ in a humid atmosphere containing $5 \% \mathrm{CO}_{2}$. The extraction media were collected at the end of this period and sterilized by passing them through a membrane filter $(0.2 \mu \mathrm{m}$ pore size; Sartorius, Göttingen, Germany). Subsequently, in pretest sealer concentrations, dilutions of sealer extracts $(1 / 2,1 / 5$,

Table 1. Composition of Root Canal Sealers Evaluated in This Study

\begin{tabular}{|c|c|}
\hline Root canal sealer & Composition \\
\hline $\begin{array}{l}\text { AH Plus (Dentsply/De Trey, Konstanz, } \\
\text { Germany) }\end{array}$ & $\begin{array}{l}\text { Paste A: bisphenol-A epoxy resin, bisphenol-F epoxy resin, calcium tungstate, zirconium } \\
\text { oxide, silica, iron oxide pigments } \\
\text { Paste B: dibenzyldiamine, aminoadamantane, tricyclodecane-diamine, calcium tungstate, } \\
\text { zirconium oxide, silica, silicone oil }\end{array}$ \\
\hline $\begin{array}{l}\text { Pulp Canal Sealer EWT (SybronEndo, } \\
\text { Glendora, CA, USA) }\end{array}$ & $\begin{array}{l}\text { Powder: silver powder, zinc oxide, thymol iodide, dimeric acid resin } \\
\text { Liquid: clove oil, canada balsam }\end{array}$ \\
\hline $\begin{array}{l}\text { BioRoot RCS (Septodont, } \\
\text { St. Maur-des-Fosses, France) }\end{array}$ & $\begin{array}{l}\text { Powder: tricalcium silicate, zirconium oxide, povidone } \\
\text { Liquid: aqueous solution of calcium chloride and olycarboxylate }\end{array}$ \\
\hline $\begin{array}{l}\text { Well-Root ST (Vericom, Chuncheon, } \\
\text { Korea) }\end{array}$ & Calcium aluminosilicate compound, zirconium oxide, filler, thickening agent \\
\hline
\end{tabular}


and $1 / 10$ dilutions) were determined.

\section{Cell culture condition}

The MC3T3-E1 mouse pre-osteoblast cell line was obtained from the American Type Culture Collection (Manassas, VA, USA). The MC3T3-E1 cells were cultured in $\alpha$-MEM containing $10 \%$ fetal bovine serum (FBS; Gibco, Life Technologies, Grand Island, NY, USA) supplemented with an antibiotic-antimycotic solution (100 units $/ \mathrm{ml}$ penicillin, $100 \mathrm{~g} / \mathrm{ml}$ streptomycin, and $250 \mathrm{ng} / \mathrm{ml}$ Fungizone ${ }^{R}$ (amphotericin B); Gibco) at $37^{\circ} \mathrm{C}$ in a humidified atmosphere with $5 \% \mathrm{CO}_{2}$. The cell culture medium was replaced every 3 days.

A AH plus

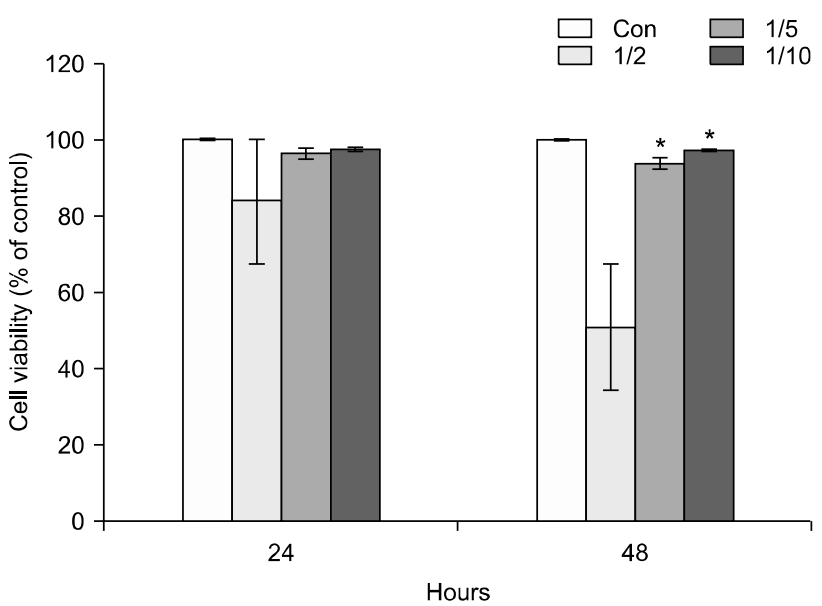

C

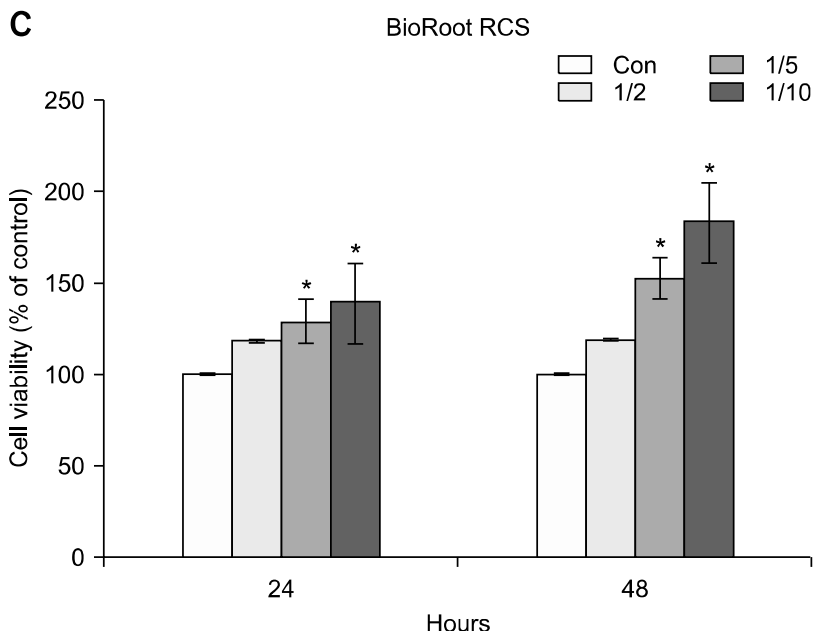

\section{Cell viability assay}

The cell viability of various root canal sealers was measured using the water-soluble tetrazolium-8 (WST-8; 2-(2-methoxy-4-nitrophenyl)-3-(4-nitrophenyl)-5-(2,4-dis ulfophenyl)-2H-tetrazolium) assay (MediFab, Seoul, Korea). MC3T3-E1 cells were seeded in 96-well plates at an equal density of $1 \times 10^{4}$ cells per wells. After overnight incubation, the cells were cultured in the presence or absence (control) of sealer extracts $(1 / 2,1 / 5$, and $1 / 10$ dilutions) in a humidified atmosphere of $5 \% \mathrm{CO}_{2}$ at $37^{\circ} \mathrm{C}$ for 24 and 48 hours. The cells were incubated with WST- 8 solution ( $5 \mu \mathrm{L} /$ well) for 2 hours. Then, absorbance at $450 \mathrm{~nm}$ was

B Pulp Canal Sealer EWT

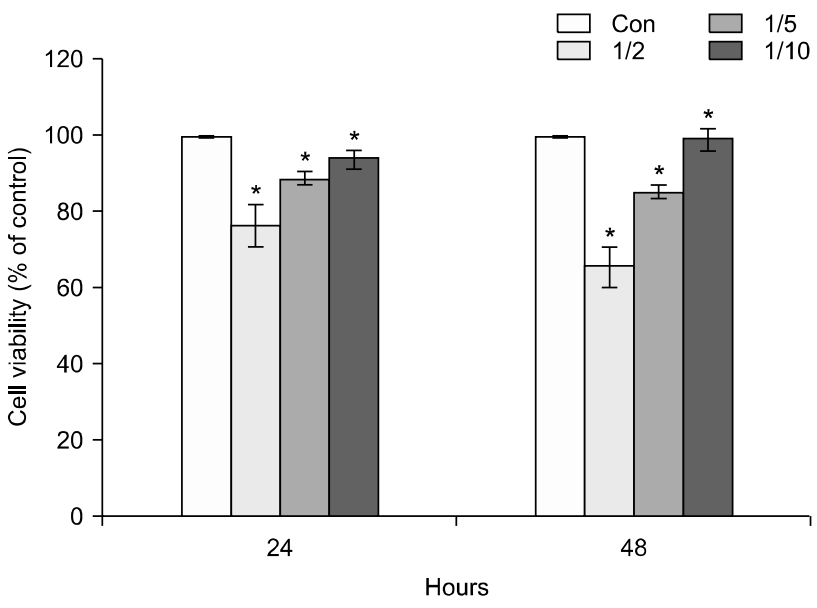

D Well-Root ST

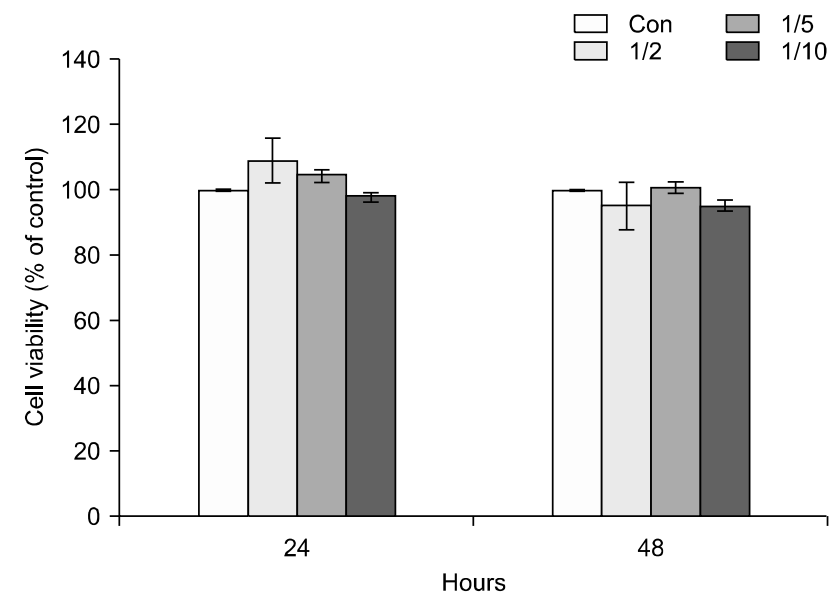

Fig. 1. Cell viability on various dilution of four root canal sealers. The percentage of cell viability was evaluated by the WST-8 assay using (A) AH Plus, (B) Pulp Canal Sealer EWT, (C) BioRoot RCS, and (D) Well-Root ST at 24 and 48 hours. MC3T3-E1 cells were cultured in extraction media derived from four sealers $(1 / 2,1 / 5$, and $1 / 10$ dilutions). Groups with letters above the data bar showed statistically significant results compared to the control group $\left(n=3,{ }^{*} p<0.05\right)$. Con: control. 
measured using a microplate reader (Bio-Rad, Hercules, CA, USA).

\section{Alkaline phosphatase (ALP) activity assay}

MC3T3-E1 cells were cultured for 3, 5, and 10 days in osteogenic supplements (OS; $\alpha$-MEM with $10 \%$ FBS with $50 \mu \mathrm{g} / \mathrm{mL}$ ascorbic acid and $10 \mathrm{mM} \beta$-glycerophosphate) at $1 \times 10^{4}$ cells per well in 96-well plates with sealer extracts $(1 / 2,1 / 5$, and $1 / 10$ dilutions). ALP activity was analyzed following the protocol recommended in the SensoLyte ${ }^{\circledR}$ pNPP ALP assay colorimetric kit (Anaspec, San Jose, CA, USA). Absorbance was measured spectrophotometrically at $405 \mathrm{~nm}$ using a microplate reader
(Bio-Rad).

\section{Mineralization assay}

To quantify mineralization potential, MC3T3-E1 cells were cultured for 5 days in OS at $3 \times 10^{4}$ cells per well in a 24-well plate with sealer extracts $(1 / 2,1 / 5$, and $1 / 10$ dilutions). After 5 days, cells were stained with $2 \%$ Alizarin Red S (Sigma-Aldrich, St. Louis, MO, USA). At the end of the culture period, calcium deposits within cells and the extracellular matrix were visualized using bright-field microscopy (Olympus Corporation, Tokyo, Japan).
A

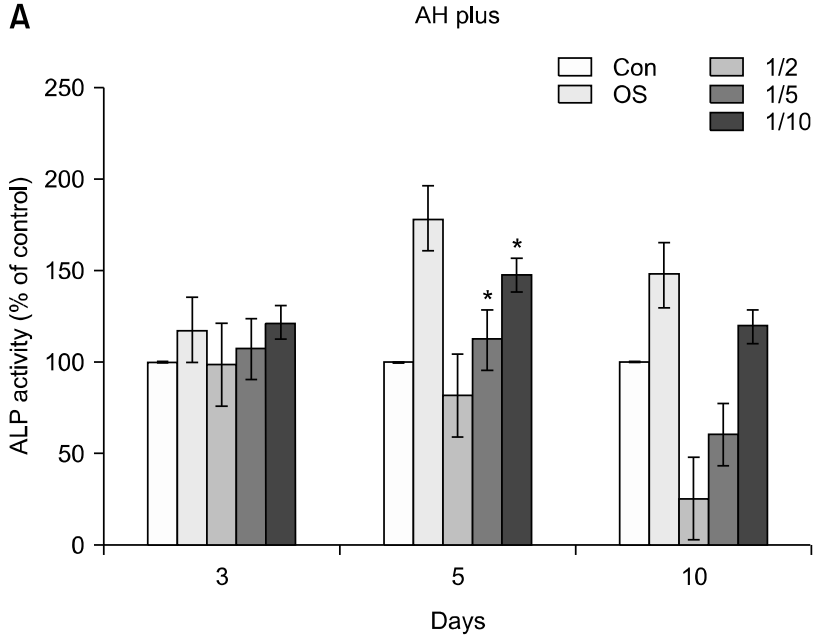

C

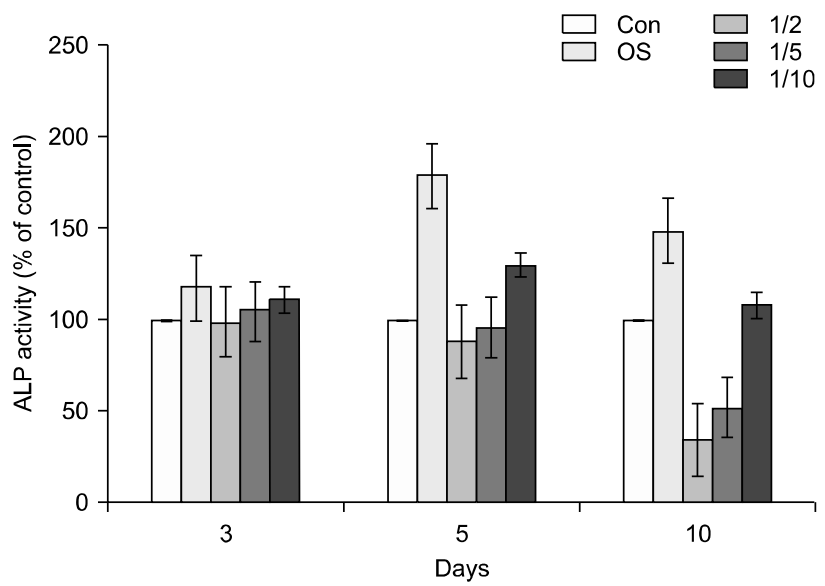

B

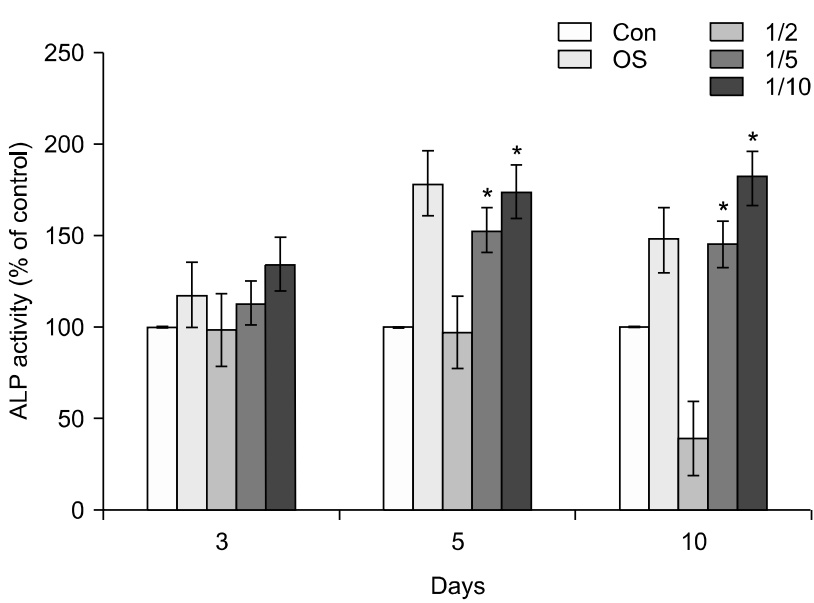

D Well-Root ST

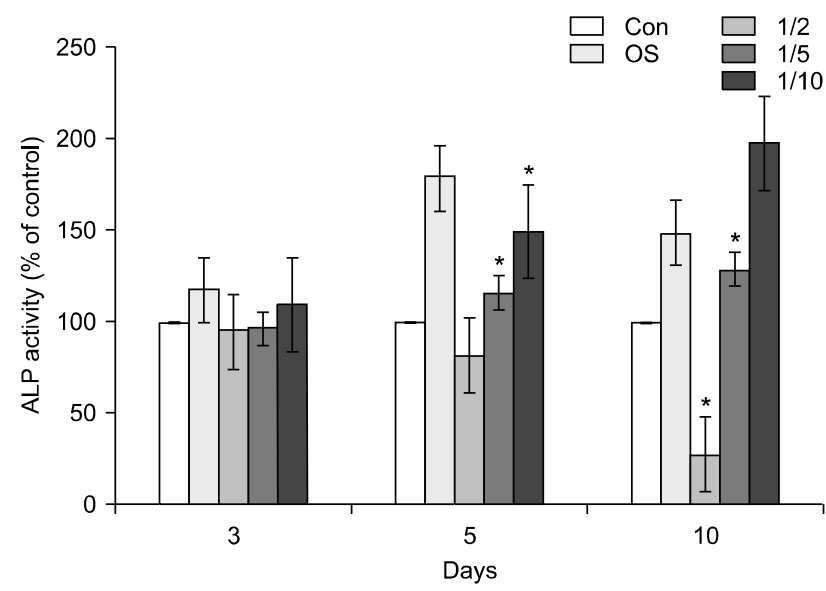

Fig. 2. Alkaline phosphatase (ALP) activity on various dilution of four root canal sealers. ALP activity demonstrated the osteogenic differentiation potential of the sealer extracts (A) AH Plus, (B) Pulp Canal Sealer EWT, (C) BioRoot RCS, and (D) Well-Root ST. The cells were incubated for 3,5 , and 10 days in sealer extracts $(1 / 2,1 / 5$, and $1 / 10$ dilutions) with odontogenic supplements (OS; $\alpha$-MEM with $10 \%$ fetal bovine serum, $50 \mu \mathrm{g} / \mathrm{ml}$ ascorbic acid, and $10 \mathrm{mM} \beta$-glycerophosphate). Groups with letters above the data bar are statistically significant results compared to the control group $\left(n=3,{ }^{*} p<0.05\right)$. 


\section{Statistical analysis}

All data are presented as mean \pm standard deviation from a minimum of three replicates. The means of the treatment groups were compared to those of controls using the Student's t-test in SPSS Statistics 25 (IBM Corp., Armonk, NY, USA), and the statistical significance level was $\mathrm{p}<0.05$.

\section{Results}

\section{Cytocompatibillity of MC3T3-E1 with four different root canal sealers}

We determined the cell viability of each root canal sealer extract (various dilutions: 1/2, 1/5, and 1/10) (Fig. 1). At 1/10 dilution, AH26 Plus and Pulp Canal Sealer EWT showed nearly $100 \%$ cell viability in MC3T3-E1 cells up to until 48 hours but showed decreased cell viability at $1 / 2$ dilution compared to the control (without sealer extracts). Among all experimental groups, BioRoot RCS showed the highest cell viability up to 48 hours $(\mathrm{p}<$ 0.05 ). Well-Root ST had similar cell viability compared to the controls without a cytotoxic effect at dilutions ranging from $1 / 2$ to $1 / 10$.

\section{Osteogenic differentiation capacity of four different root canal sealers}

The early differentiation of MC3T3-E1 osteoblasts was evaluated as a function of ALP activity. Data on ALP ratios $(\%)$ in the presence of different sealer extracts are shown in Fig. 2. At dilutions ranging from $1 / 5$ to $1 / 10$, sealers exhibited higher ALP activity than the control (without sealer extracts). In all experimental groups, the ALP index tended to increase with the lower sealer concentrations. At 1/10 dilution, Pulp Canal Sealer EWT and Well-Root ST exhibited significantly higher ALP activity than the control groups $(\mathrm{p}<0.05)$.

Mineralization was assessed by Alizarin Red S staining. As expected, OS increased mineralized nodule formation in a time-dependent manner compared to the control. At $1 / 10$ dilution, the formation of mineralized nodule formation was greater with Pulp Canal Sealer EWT and Well-Root ST, but not with other sealer extracts (Fig. 3).

\section{Discussion}

The importance of biological compatibility of root canal sealers is based on the fact that, during endodontic treatment, root canal sealers may exceed the root apex and penetrate periodontal tissues ${ }^{16)}$. The tissue response to these materials may influence root canal treatment outcomes $^{17)}$. Biocompatible and bioactive root canal sealers can promote the reorganization of inflamed tissue and wound healing in apical periodontitis ${ }^{18)}$. This study aimed to evaluate the biocompatibility and osteoblastic mineralization activity of various sealers.

In this study, the cell viability of four different sealers was analyzed using the WST-8 assay. AH Plus, a resin-based canal sealer, is known for its low bioactive potential $^{9)}$. This study confirmed the cytotoxic potential of AH Plus sealer and Pulp Canal Sealer EWT. In the case of AH Plus, despite the small amount of formaldehyde released, cytotoxicity is high because epoxy resin, one of

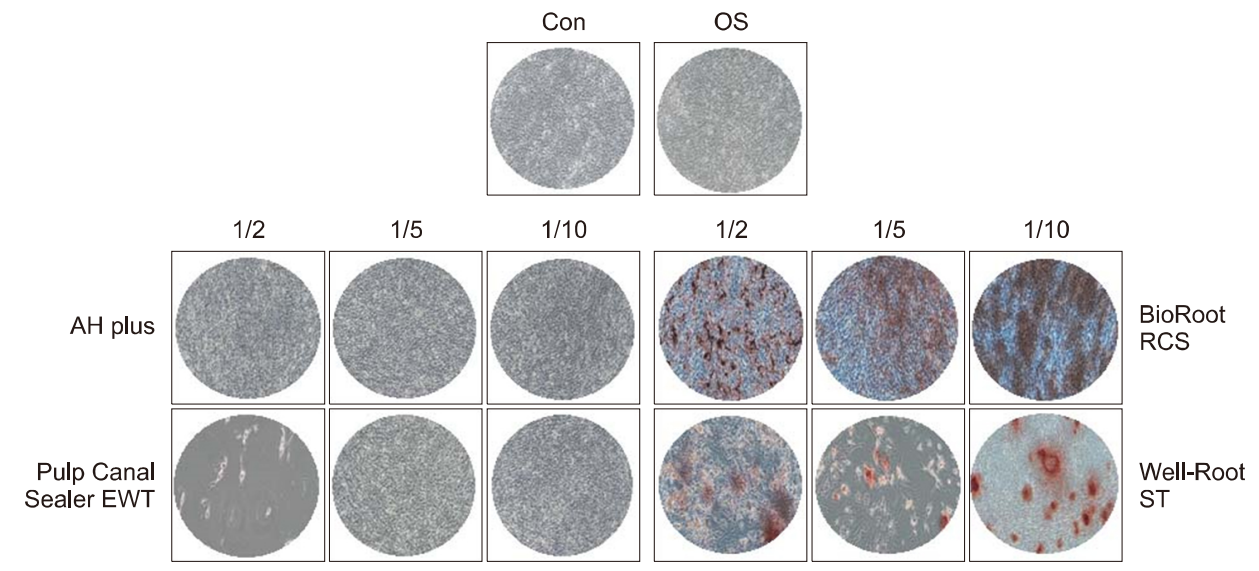

Fig. 3. Mineralization effects on various dilution of four root canal sealers. Mineralized nodule formation was assessed by staining with Alizarin Red S (light microscope, $\times 100$ ). The cells were incubated in sealer extracts $(1 / 2,1 / 5$, and $1 / 10$ dilutions) with odontogenic supplements (OS; $\alpha$-MEM with $10 \% \mathrm{FBS}, 50 \mu \mathrm{g} / \mathrm{ml}$ ascorbic acid, and $10 \mathrm{mM} \beta$-glycerophosphate) medium for 10 days. The data are representative of three independent experiments. Con: control. 
the main components, has been identified as a toxic factor ${ }^{19)}$. The epoxy resin present in AH Plus is a mutagen that may cause cell DNA strand breaks ${ }^{20)}$. However, other studies have shown no significant periapical tissue damage even with extrusion of AH Plus sealer, implying low cytotoxic potential ${ }^{21)}$.

Zinc oxide eugenol type sealers, Pulp Canal Sealer EWT, are irritating mainly because of eugenol ${ }^{10)}$. Nevertheless, Pulp Canal Sealer EWT, also known as a bioceramic sealer, has become increasingly popular owing to its ability to bond to dentin and form hydroxyapatite. Reports show that this sealer is biocompatible and stable in biological environments ${ }^{9)}$.

BioRoot RCS is a novel bioceramic endodontic sealer, with higher cell proliferation rates, than other sealers, such as epoxy resin-based and zinc oxide-eugenol sealers ${ }^{13}$. Our study showed that BioRoot RCS was the only sealer with good cell viability at all extract concentrations (Fig. 1).

Well-Root ST is a premixed, ready-to-use, injectable bioceramic cement paste developed for permanent obturation of the root canal. Well-Root, as described by the manufacturer, consists of zirconium oxide, calcium silicate, filler, and thickening agents. According to the results of this study, MTA calcium silicate-based sealers (Well-Root ST) appear to be more biocompatible and less cytotoxic than epoxy resin-based sealers. Well-Root ST, a bioceramic-based sealer composed of bioceramic powder and carrier, exhibits biocompatibility, biomineralization, and osteoconductivity ${ }^{22,23)}$.

Assessment of the activity of ALP, an enzyme expressed during the early maturation of osteoblasts, can determine the potential of inducing mineralized tissue formation ${ }^{24)}$. Studies revealed that ALP activity in osteoblastic MC3T3-E1 cells $^{25)}$ showed significant suppression with dental resin-based materials. Formaldehyde released from resin-based sealers can significantly decrease ALP activity in rats ${ }^{26)}$.

Alizarin Red S staining evaluates the mineralization activity of a substance by identifying calcium deposits in cell culture. The Alizarin Red S staining kit stains calcium deposits in red, allowing observation of calcium mineralization. The results showed that AH Plus and Pulp Canal Sealer EWT could inhibit bone healing. Therefore, care should be taken to prevent extrusion of AH Plus, and Pulp Canal Sealer EWT is not extruded out of the apical foramen ${ }^{27)}$.

This study highlights the significance of the first time that the four materials exhibit different biological activities. Within the limitations of this in vitro study, these results suggest that composition of root canal sealers can exert varying influences on biocompatibility and osteoblastic differentiation.

\section{Notes}

\section{Conflict of interest}

No potential conflict of interest relevant to this article was reported.

\section{Ethical approval}

This project does not require IRB review because it is an experimental paper using commercially available cells.

\section{Author contributions}

Conceptualization: Sang-Im Lee and Nu-Ri Jun. Data acquisition: Nu-Ri Jun. Formal analysis: Sang-Im Lee, Sun-Kyung Lee, and Nu-Ri Jun. Funding: Sang-Im Lee. Supervision: Sang-Im Lee. Writing-original draft: Sang-Im Lee, Sun-Kyung Lee, and Nu-Ri Jun. Writing-review \& editing: Sang-Im Lee.

\section{ORCID}

Nu-Ri Jun, https://orcid.org/0000-0002-7293-0587

Sun-Kyung Lee, https://orcid.org/0000-0003-3955-939X

Sang-Im Lee, https://orcid.org/0000-0003-2635-6876

\section{Acknowledgements}

This research was supported by the National Research Foundation of Korea (NRF) grant funded by the Korea government (MSIP) (No. 2018R1D1A1B07051253).

\section{References}

1. Ricucci D, Rôças IN, Alves FR, Loghin S, Siqueira JF Jr: Apically extruded sealers: fate and influence on treatment outcome. J Endod 42: 243-249, 2016. 
https://doi.org/10.1016/j.joen.2015.11.020

2. Troiano G, Perrone D, Dioguardi M, Buonavoglia A, Ardito F, Lo Muzio L: In vitro evaluation of the cytotoxic activity of three epoxy resin-based endodontic sealers. Dent Mater J 37: 374-378, 2018. https://doi.org/10.4012/dmj.2017-148

3. Chandra A: Discuss the factors that affect the outcome of endodontic treatment. Aust Endod J 35: 98-107, 2009. https://doi.org/10.1111/j.1747-4477.2009.00199.x

4. Bernáth M, Szabó J: Tissue reaction initiated by different sealers. Int Endod J 36: 256-261, 2003. https://doi.org/10.1046/j.1365-2591.2003.00662.x

5. Holland R, Gomes JE Filho, Cintra LTA, Queiroz ÍOA, Estrela $\mathrm{C}$ : Factors affecting the periapical healing process of endodontically treated teeth. J Appl Oral Sci 25: 465-476, 2017. https://doi.org/10.1590/1678-7757-2016-0464

6. Ghanaati S, Willershausen I, Barbeck M, et al: Tissue reaction to sealing materials: different view at biocompatibility. Eur J Med Res 15: 483-492, 2010. https://doi.org/10.1186/2047-783x-15-11-483

7. Victoria-Escandell A, Ibañez-Cabellos JS, de Cutanda SB, et al.: Cellular responses in human dental pulp stem cells treated with three endodontic materials. Stem Cells Int 2017: 8920356, 2017. https://doi.org/10.1155/2017/8920356

8. Almeida MM, Rodrigues CT, Matos AA, et al.: Analysis of the physicochemical properties, cytotoxicity and volumetric changes of AH Plus, MTA Fillapex and TotalFill BC Sealer. J Clin Exp Dent 12: e1058-e1065, 2020. https://doi.org/10.4317/jced.57527

9. Willershausen I, Callaway A, Briseño B, Willershausen B: In vitro analysis of the cytotoxicity and the antimicrobial effect of four endodontic sealers. Head Face Med 7: 15, 2011. https://doi.org/10.1186/1746-160X-7-15

10. Loushine BA, Bryan TE, Looney SW, et al.: Setting properties and cytotoxicity evaluation of a premixed bioceramic root canal sealer. J Endod 37: 673-677, 2011. https://doi.org/10.1016/j.joen.2011.01.003

11. Gomes-Filho JE, Gomes BP, Zaia AA, Ferraz CR, Souza-Filho FJ: Evaluation of the biocompatibility of root canal sealers using subcutaneous implants. J Appl Oral Sci 15: 186-194, 2007. https://doi.org/10.1590/s1678-77572007000300007

12. Taraslia V, Anastasiadou E, Lignou C, Keratiotis G, Agrafioti A, Kontakiotis EG: Assessment of cell viability in four novel endodontic sealers. Eur J Dent 12: 287-291, 2018. https://doi.org/10.4103/ejd.ejd_9_18

13. Jung S, Sielker S, Hanisch MR, Libricht V, Schäfer E, Dammaschke T: Cytotoxic effects of four different root canal sealers on human osteoblasts. PLoS One 13: e0194467, 2018. https://doi.org/10.1371/journal.pone.0194467

14. Taddei P, Tinti A, Gandolfi MG, Rossi PL, Prati C: Vibrational study on the bioactivity of Portland cement-based materials for endodontic use. J Mol Struct 924-926: 548-554, 2009. https://doi.org/10.1016/j.molstruc.2008.11.002

15. Gomes-Filho JE, Watanabe S, Bernabé PF, de Moraes Costa MT: A mineral trioxide aggregate sealer stimulated mineralization. J Endod 35: 256-260, 2009. https://doi.org/10.1016/j.joen.2008.11.006

16. Geurtsen W, Leyhausen G: Biological aspects of root canal filling materials--histocompatibility,cytotoxicity, and mutagenicity. Clin Oral Investig 1: 5-11, 1997. https://doi.org/10.1007/s007840050002

17. Lodiene G, Morisbak E, Bruzell E, Ørstavik D: Toxicity evaluation of root canal sealers in vitro. Int Endod J 41: 72-77, 2008. https://doi.org/10.1111/j.1365-2591.2007.01321.x

18. Seo DG, Lee D, Kim YM, Song D, Kim SY: Biocompatibility and mineralization activity of three calcium silicate-based root canal sealers compared to conventional resin-based sealer in human dental pulp stem cells. Materials (Basel) 12: 2482, 2019. https://doi.org/10.3390/ma12152482

19. Kim HJ, Baek SH, Lee WC, Park HS, Bae KS: Cytotoxicity of resin-based root canal sealer, adseal. J Korean Acad Conserv Dent 29: 498-503, 2004. https://doi.org/10.5395/JKACD.2004.29.6.498

20. Schweikl H, Schmalz G, Federlin M: Mutagenicity of the root canal sealer AHPlus in the Ames test. Clin Oral Investig 2: 125-129, 1998. https://doi.org/10.1007/s007840050057

21. Hubbe KL, de Oliveira KV, Coelho BS, Baratto-Filho F: AH Plus extrusion into periapical tissue: literature review of main related properties and report of clinical cases. Revis Sul-Bras Odontol 13: 280-288, 2016. 
22. Lee JK, Kim S, Lee S, Kim HC, Kim E: In vitro comparison of biocompatibility of calcium silicate-based root canal sealers. Materials (Basel) 12: 2411, 2019.

https://doi.org/10.3390/ma12152411

23. Donnermeyer D, Bürklein S, Dammaschke T, Schäfer E: Endodontic sealers based on calcium silicates: a systematic review. Odontology 107: 421-436, 2019. https://doi.org/10.1007/s10266-018-0400-3

24. Zordan-Bronzel CL, Tanomaru-Filho M, Rodrigues EM, Chávez-Andrade GM, Faria G, Guerreiro-Tanomaru JM: Cytocompatibility, bioactive potential and antimicrobial activity of an experimental calcium silicate-based endodontic sealer. Int Endod J 52: 979-986, 2019.

https://doi.org/10.1111/iej.13086
25. Imazato S, Horikawa D, Ogata K, Kinomoto Y, Ebisu S: Responses of MC3T3-E1 cells to three dental resin-based restorative materials. J Biomed Mater Res A 76: 765-772, 2006.

https://doi.org/10.1002/jbm.a.30422

26. Gulec M, Gurel A, Armutcu F: Vitamin E protects against oxidative damage caused by formaldehyde in the liver and plasma of rats. Mol Cell Biochem 290: 61-67, 2006. https://doi.org/10.1007/s11010-006-9165-Z

27. Huang FM, Yang SF, Chang YC: Effects of root canal sealers on alkaline phosphatase in human osteoblastic cells. J Endod 36: 1230-1233, 2010. https://doi.org/10.1016/j.joen.2010.03.001 